\title{
Artes y oficios artísticos en Granada a mediados del siglo XVIII
}

\author{
Juan Jesús LóPez MuÑoz y Miguel LuIS LóPEz MuÑoz
}

\section{INTRODUCCIÓN}

El Catastro de Ensenada, realizado a instancias del rey Fernando VI a partir de 1749, es sin duda alguna la fuente económica de conjunto más amplia en la España del siglo XVIII. Su amplitud y riqueza de datos la hace imprescindible para conocer la realidad de ciudades y pueblos, de la Iglesia y de las diferentes capas sociales.

Su minuciosidad responde a ese afán ilustrado por conocer la realidad como paso previo para reformarla. En el caso concreto del Catastro, el móvil directo para su elaboración era el deseo de sustituir la compleja, y a menudo poco eficaz, realidad fiscal de la monarquía hispánica por el sistema más racional de una contribución única ${ }^{1}$.

El intento reformista, como tantos otros, se frustró, pero nos legó una riquísima documentación. Si los libros de Respuestas Generales resultan fundamentales a los investigadores para establecer el perfil socio-económico de cada localidad, los de Respuestas Particulares ofrecen una radiografía detallada de la composición socio-laboral de la población, siendo especialmente útil para los grupos humanos peor conocidos por otras fuentes, como ocurre con el amplísimo y heterogéneo tercer estado.

En ese extenso conjunto nos detendremos ahora para analizar diversos oficios de la ciudad de Granada, sobre datos del Catastro que pueden fecharse en 1752.

\footnotetext{
- Vid. con todo detalle en la obra clásica de Matilla Tascón, A. La Única Contribución y el Catastro de Ensenada. Madrid, 1947.
} 
La documentación catastral es muy amplia. Para el presente estudio se han utilizado diversos libros ${ }^{2}$ :

- Vecindarios por parroquias (dos libros): informan sobre los miembros de cada familia, sus edades y ocupación laboral.

- Libros de producible por personas (cinco libros): con datos sobre fincas rústicas o urbanas y sus rentas, ingresos laborales, etc...

- Libros de producible general por oficios (dos libros): contienen el grado laboral de cada trabajador, lo regulado por el ejercicio del oficio...

- Otros libros: relaciones sueltas de vecinos, libros de mujeres, etc...

Los datos que ofrecen pueden entrecruzarse. Esta labor permite un conocimiento más completo del colectivo humano objeto de estudio. Los datos, sin embargo, no siempre son coincidentes (por ejemplo, asignación a parroquias distintas, consignación de grados laborales discordantes). En cualquier caso, los datos obtenidos y sistematizados permiten una radiografía muy interesante y sugerente sobre la situación socio-familiar de esos artesanos, cuyos oficios se considerarían hoy en gran medida artísticos.

Los oficios elegidos son ocho, enumerados por orden decreciente del número de personas dedicadas a ellos: carpinteros, plateros, canteros, pintores, doradores, talladores, escultores y bordadores.

La carpintería, rebasando el campo de lo estrictamente artístico, tenía una indudable aplicación en la actividad constructiva de inmuebles; de hecho, en origen muchos carpinteros fueron también albañiles. Es la llamada carpintería "de obra de fuera» (antiguamente llamada también «de lo blanco», según el libro escrito por Diego López de Arenas): «parte de la arquitectura que enseña el corte y colocación de las maderas en un edificio " ${ }^{3}$. Junto a ella se contiene en las primeras ordenanzas de los carpinteros granadinos (1528) la carpintería «de lo prieto» — tareas de lazo y mocárabes, arcones, mesas, muebles en general, etc.--, además de las actividades de entalladores, vigoleros y organistas, que más tarde se individualizaron. Al carpintero se le exigian ciertos conocimientos de geometría junto a la habilidad manual en su trabajo («que labre limpio y justo de sus manos») ${ }^{4}$.

2 En Archivo de la Real Chancillería de Granada (A.R.Ch.G.), Catastro, libros 315-316, 318$322,326-327$ y otros. La información ofrecida en este trabajo procede de esos libros.

3 Rejon de SIlva, Diego Antonio. Diccionario de las nobles Artes para instrucción de los Aficionados y uso de los Profesores. Segovia, 1788, pág. 52. Elegimos para estas «definiciones» un diccionario cercano en el tiempo a la época estudidada.

4 Ordenanzas que los muy ilustres y magníficos señores Granada mandaron guardar para la buena governación de su república. Granada, 1672 (1\%. ed. 1552), fol. 173. 
Las ordenanzas renovadas de 1616 agrupaban solamente a carpinteros y ensambladores, aunque en otros lugares estos últimos formaban grupo independiente (como también los adornistas, tallistas y escultores de ornatos), fuera de la «congregación gremial», según Rejón de Silva. El oficio de ensamblador consistía en "la unión que se hace de las maderas en varias posiciones y por medio de distintos cortes» ${ }^{5}$.

Los plateros se encargaban de fabricar piezas de oro y plata. En Granada sus ordenanzas fueron promulgadas en 1531 y completadas en $1538^{6}$. Desde 1529 existían ya las ordenanzas de los doradores. En origen se dedicaban al trabajo del metal, para fabricar particularmente piezas doradas con destino a armas y arneses; después se generalizó entre ellos el trabajo de hojas de oro para aplicar a diversas superficies. Tanto plateros como doradores estaban sujetos, por el valor intrínseco de la materia prima utilizada, a férreos controles de calidad por parte de las autoridades gremiales ${ }^{7}$.

La cantería es un oficio realmente manual, más ligado a la extracción y corte de sillares que al diseño de su disposición. El cantero «corta, labra y sienta las piedras para los edificios. Llámase también picapedrero " ${ }^{8}$.

Las ordenanzas del arte de la pintura para Granada datan de 1525, incluyendo entre sus tareas, objeto de examen de maestría, el uso del pincel y las superposiciones doradas. Desde el principio se estableció un fuerte control sobre las tablas procedentes de Flandes, para velar por su calidad y evitar fraudes ${ }^{9}$, pero también para proteger a los pintores locales.

Del escultor se distingue claramente el tallista o entallador, que se encarga de «hacer ornatos o figuras de baxorrelieve para los frisos y tableros de arquitectura» ${ }^{10}$. Las ordenanzas granadinas son en este caso bastante explícitas: «labrar por su manos retablos de grande arte, pilares, revestidos y esmortidos con sus tabernáculos; y repisas para imágenes y tumbas y chambranas trastocadas con sus guardapolvos en buelta redonda y hazer tabernáculos de grande arte y sillas de coros ricos» ${ }^{11}$.

5 REJón DE SILVA, D.A., Diccionario..., pág. 90. En Granada mostraban su suficiencia en retablos y sillas de coro según las ordenanzas, prueba en las que se equiparaba su maestría a la del entallador.

${ }_{6}$ Vid. su contenido en Bertos Herrera, Ma . del Pilar. El tema de la Eucaristía en el arte de Granada y su Provincia. Granada, 1986, pág. 265 y ss.

Aspectos técnicos y normativa del siglo xvil en TaAmullas y Ferreras, José. Promtuario y guia de artífices plateros,... Madrid, 1734.

s Rejón de Silva, D. A., Diccionario..., pág. 48.

9 Vid. Ordenanzas..., fols. 138-139. Se establecen tres maestrías distintas: pintor de sargas, de pincel y asentador de oro.

10 Rejón de Silva, D. A., Diccionario..., pág. 91.

"Ordenanzas..., fol. 174. 
En fin, sobre las personas dedicadas a estos oficios, incluídas en el Catastro de Ensenada, se analizarán ciertos datos (categoría laboral, parroquia de residencia, edad, ingresos anuales) que permitan una aproximación a la consideración social de esos individuos dentro del rígido marco social y laboral del Antiguo Régimen.

\section{NÚMERO DE ARTESANOS Y CATEGORIAS PROFESIONALES.}

Nuestra primera consideración se dirige a cuantificar el colectivo humano al que se refiere nuestro análisis. Estos son los datos globales:

\begin{tabular}{lcc}
\hline OFICIOS & ARTESANOS & $\%$ \\
\hline Carpinteros & 142 & 37,46 \\
Plateros & 78 & 20,58 \\
Canteros & 54 & 14,24 \\
Pintores & 39 & 10,29 \\
Doradores & 23 & 6,06 \\
Talladores & 22 & 5,80 \\
Escultores & 16 & 4,22 \\
Bordadores & 5 & 1,31 \\
\hline TOTAL & 379 & 99,96 \\
\hline
\end{tabular}

Como es lógico, la carpintería, y a distancia la platería y la cantería, ocupan el puesto principal. En los tres casos se trata de una producción dirigida a un público amplísimo, prácticamente a toda la sociedad. Las demás artes tenian unos consumidores numéricamente más reducidos, en algunos casos limitados a sectores eclesiásticos y poco más. Eso explica las diferencias de número entre unos oficios y otros. El de bordador adquiere un tinte marginal; nada extraña, por tanto, los contínuos encargos a talleres de bordados de fuera de la ciudad, sobre todo en la segunda mitad del siglo XVIII ${ }^{12}$.

El conjunto de personas dedicadas a cada uno de esos oficios distaba de ser homogéneo. La estructura gremial tradicional, introducida en Granada tras la conquista de la ciudad, se plasmó con claridad en las Ordenanzas publicadas en 1552, que recogían las clásicas categorías de maestro, oficial

12 EIsman LASAga, Carmen. El arte del bordado en Granada. Siglos XVI al XVIII Granada, 1989, pág. 23. La autora dedica a los bordadores del siglo XVIII las páginas 129 a 142. 
y aprendiz en cada oficio ${ }^{13}$. Hay que ponderar la importancia sostenida de los gremios durante el Antiguo Régimen. Son integrantes fundamentales de la sociedad urbana barroca, especialmente los de oficios artísticos, "cuya actividad se relaciona con el monopolio de la vida pública ejercido a través del ceremonial político o el rito religioso. La iglesia contrarreformista, la aristocracia urbana y las hermandades son los principales clientes de estos gremios que tienen su principal ámbito de trabajo en la fiesta o la liturgia (...) ${ }^{14}$.

Las categorías profesionales aludidas figuran en el Catastro, si bien la consignación de aprendices es muy irregular. En cambio, la de maestros y oficiales resulta muy exhaustiva en la documentación catastral, a causa de los fines fiscales perseguidos con su realización:

\begin{tabular}{lrrccc}
\hline OFICIO & MAEST. & OFICIAL & APREND. & SIN DAT & TOTAL \\
\hline Carpinteros & 65 & 69 & 5 & 3 & 142 \\
Plateros & 36 & 39 & 3 & & 78 \\
Canteros & 10 & 39 & 1 & 4 & 54 \\
Pintores & 19 & 14 & 2 & 4 & 39 \\
Doradores & 10 & 9 & 2 & 2 & 23 \\
Talladores & 6 & 13 & 2 & 1 & 22 \\
Escultores & 13 & 2 & & 1 & 16 \\
Bordadores & 3 & 2 & & & 5
\end{tabular}

\begin{tabular}{llllll}
\hline TOTAL & 162 & 187 & 15 & 15 & 379 \\
\hline
\end{tabular}

En líneas generales, el número de maestros iguala al de oficiales, al menos en los dos oficios mayoritarios de los considerados, carpinteros y plateros. Ello pone de manifiesto, por un lado, las pequeñas dimensiones de los talleres artesanales (de carácter casi exclusivamente familiar) y, por otro, la relativa facilidad para acceder al grado superior de la maestría.

13 Vid. sobre Granada las obras clásicas de VALl.ADAR, Francisco de Paula. Las Ordenanzas de Granada y las artes industriales granadinas. Granada, 1915, y Moreno CASAdo, José. Las Ordenanzas gremiales de Granada en el siglo XVI. Granada, 1948. Para la estructura gremial en la España del siglo XVIII, junto a numerosas obras clásicas de comienzos de nuestro siglo, deben destacarse Molas RIBALTA, Pedro. Los Gremios barceloneses del siglo XVII. La estructura corporativa ante el comienzo de la revolución industrial. Madrid, 1970, y VILLAS TINoco, Siro. Los gremios malagueños (1700-1746). Málaga, 1982, 2 vols.

14 Henares CuÉllar, Ignacio. «La escultura en la sociedad y el pensamiento barrocos», en Pedro de Mena. Tercer centenario de su muerte. 1688-1988. Málaga, 1989, pág. 25. Sobre los gremios artísticos granadinos vid. MORENo ROMERA, Bibiana. Artistas y artesanos granadinos en la segunda mitad del siglo XVII. Documentación y estudio histórico de los gremios. Tesis doctoral, Universidad de Granada, 1994. 
Sin embargo, esa nivelación se quiebra en determinados oficios:

- Unas veces a favor de la figura del maestro: dos maestros por cada oficial entre los pintores, casi seis maestros por oficial entre los escultores.

- Otras veces el grado de oficial es dominante: dos oficiales por cada maestro entre los talladores, tres oficiales por maestro entre los canteros.

La observación de tales datos permite formular una reflexión a modo de hipótesis que ayude a precisar la desdibujada frontera entre artistas y artesanos: el grado de maestro es dominante en aquellos oficios que pueden considerarse "artísticos» (pintura, escultura). Para su desempeño con éxito se requiere algo más que una especial cualificación técnica y es un cierto talento artístico, a pesar de las repetidas variaciones de taller tardobarrocas. Son, asimismo, oficios con un campo laboral reducido, que no permiten, por tanto, la labor productiva de un gran taller. Sin duda, la proporción se dispara entre los escultores por ser un oficio netamente artístico, ya que entre el censo de pintores debían estar incluidos también los pintores "de lo basto".

En contraposición, la labor de cantería exige un mayor número de trabajadores empleados, dada la dificultad del trabajo y la envergadura de la materia empleada. Con frecuencia los maestros de cantería eran en realidad los propietarios de las canteras o los agentes encargados de su explotación; en cierto modo, el concepto de empresa podría asimilarse al ámbito de los canteros. Reputados maestros de obras fueron propietarios de canteras en Sierra Elvira como Francisco Rodríguez Navajas y su sobrino José de Bada y Navajas ${ }^{15}$.

Para acceder a la maestría bastaba con mostrar la suficiencia en el examen correspondiente, sino que había que satisfacer unos derechos de examen a menudo elevados $y$, en muchos casos, pagar una cuantiosa suma en concepto de licencia para la apertura de tienda. Ello imponía un cierto grado de condicionamiento económico. El maestro de platero Félix José Valdivia, por ejempio, trabajaba simplemente como oficial, pues «por sus cortos (h)aberes no puede hacer travajo de tal maestro" ${ }^{16}$. Es posible que otras contradicciones, poco numerosas por otro lado, en cuanto a la categoría de un mismo individuo en los libros catastrales respondan a la misma causa.

15 Isla Mingorance, Encarnación. José de Bada y Navajas, arquitecto andaluz (1691-1755). Granada, 1977, págs. 45 y 55.

${ }_{16}$ A.R.Ch.G., Catastro, lib. 19. Precisamente las ordenanzas del colegio de S. Eloy de Granada denunciaban la estratagema de diversos maestros «de haverse retirado a sus casas, quitando las tiendas, diziendo no son tales plateros, a fin de no pagar lo que les corresponde en 


\section{CATEGORIAS PROFESIONALES POR OFICIOS (según el Catastro de Ensenada)}

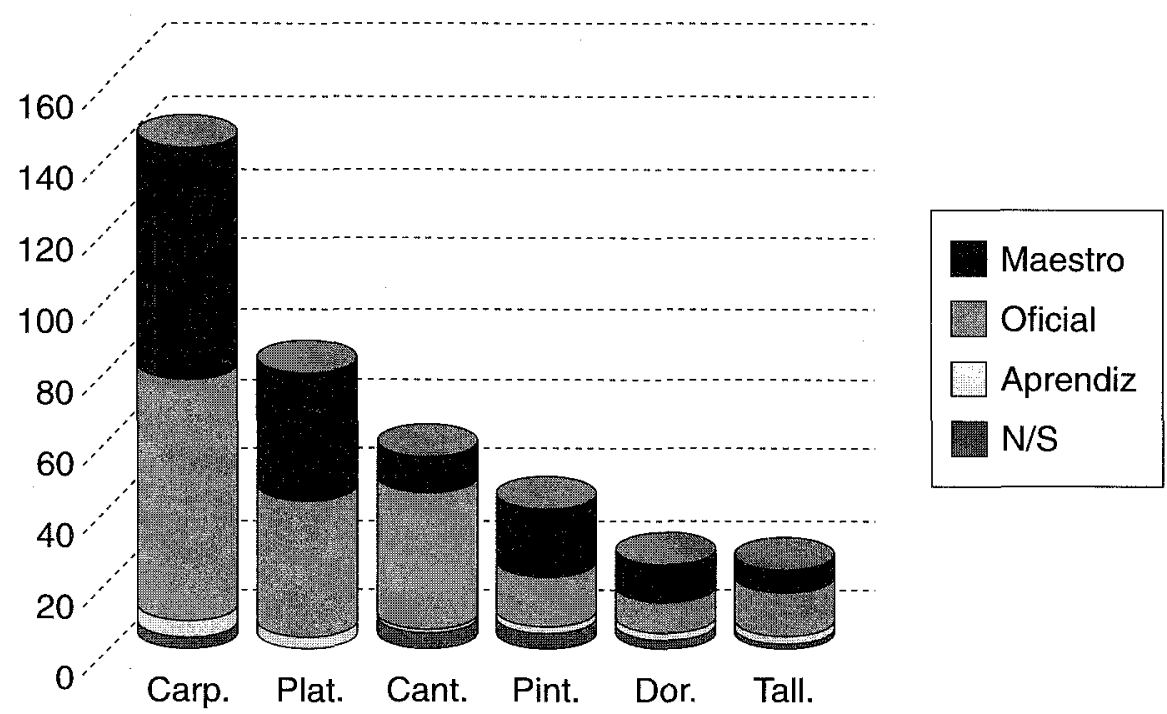

Además en el seno de los oficios se observan algunas especialidades laborales, como los bruñidores de piedra entre los canteros, los vaciadores, tiradores (del ramo textil) y batihojas entre los plateros, los artífices de buril (grabadores en realidad) contados entre los escultores ${ }^{17}$, aparejadores de pintura entre los pintores, etc... Muy raramente aparece una misma persona desempeñando dos oficios: Nicolás González de la Peña, Francisco Navarro Rivero, José del Pino y Francisco Saravia eran maestros pintores y doradores; Alejandro Salmerón era tallador y ensamblador ${ }^{18}$.

los gastos que se originan de pleytos y otros a la Congregación, ...tratando y comerciando en sus casas sijilosamente» (Biblioteca Nacional (B.N.), Manuscritos, 7554).

17 La fuente catastral nos señala a don Juan Luengo como «maestro de abrir láminas", esto es, grabador calcográfico; también era congregante del Colegio de S. ELoy de plateros, «aprobado para poner tienda en 1736" (Bertos HerRera, Ma . P. Los escultores de la plata y el oro. Granada, 1991, pág. 190). Sin embargo, tanto él como Félix Alvarado (grabador igualmente) aparecen incluidos en el resumen general del arte de la escultura.

18 En otras localidades, como Barcelona esta «duplicidad» de oficios era más común. "Normalmente se trataba de oficios, cuya extrema afinidad permitía una fácil adaptación; en cierto modo, la persona que los ejercía trataba de subsanar el excesivo fraccionamiento que la división de gremios había producido. El maestro que había comenzado una obra y tenía capacidad para terminaria, lo hacia, sin necesidad de recurrir a otra persona de distinto gremio" (MOlas RIBALTA, P., Los Gremios..., pág. 117). 
Como se ha apuntado, el número de aprendices que se consigna es irrelevante en todos los oficios. Aqui el Catastro peca claramente por defecto, si consideramos que el "aprendizaje» era una etapa fundamental en la formación del artesano o artista. Ello puede obedecer a motivos diversos:

- En muchos casos los aprendices son los propios hijos del maestro, aunque ello no se haga constar en los libros de vecindario.

- A veces, pueden confundirse con oficiales, si recibían algún tipo de gratificación por su trabajo.

- Sobre todo, la figura del aprendiz era fiscalmente irrelevante y, por consiguiente, de poco interés para los agentes encargados de elaborar la documentación catastral.

En cualquier caso, los aprendices cuentan con una edad inferior a los veinte años.

La consideración de las categorías dentro de cada oficio puede perfilarse con mayor exactitud mediante el análisis de otras fuentes. Entre ellas deben destacarse las de carácter municipal (derechos de examen, concesión de licencias de apertura, etc...), al tratarse de competencias de los ayuntamientos ${ }^{19}$.

También permite el Catastro la configuración de grupos en razón de la edad. Para ello se han agrupado los artesanos en grupos de veinte en veinte años:

\begin{tabular}{lrrrrr}
\hline OFICIO & H. 20 & $21-40$ & $41-60$ & D. 61 & TOTAL \\
\hline Carpinteros & 13 & 72 & 35 & 9 & 129 \\
Plateros & 5 & 31 & 25 & 9 & 70 \\
Canteros & 3 & 22 & 22 & 4 & 51 \\
Pintores & 5 & 20 & 7 & 2 & 34 \\
Doradores & 3 & 12 & 5 & & 20 \\
Talladores & 3 & 10 & 4 & 2 & 19 \\
Escultores & 1 & 9 & 4 & 2 & 16 \\
Bordadores & & 5 & & & 5 \\
\hline TOTAL & 33 & 181 & 102 & 28 & 344 \\
\hline
\end{tabular}

19 En el caso de los plateros, han sido utilizadas en Bertos Herrera, Ma . P. Los escultores... y en otras obras anteriores de la misma autora. 
Las cifras son claras: el $52,61 \%$ de los artesanos se encuentran en el segmento de 21 a 40 años, seguido de los que cuentan entre 41 y 60 $(29,65 \%$ del total). Los grupos extremos, como es lógico, son escasamente significativos. El abanico es, sin embargo, muy amplio: desde los diez años de Manuel de Rojas, aprendiz de pintor, los once de Gabriel López, aprendiz de dorador, o los doce de Francisco Fernández y de José López, ambos aprendices de carpintería, hasta los ochenta del maestro del mismo oficio, José Pavón, que ya no ejercía su profesión.

La división por grupos de edad se encuentra bastante equilibrada en todos los oficios, con la excepción de los bordadores, todos ellos comprendidos entre los 21 y los 40 años. No obstante, puede destacarse la relativa importancia de los menores de 20 años entre los doradores y talladores, la acusada importancia del grupo entre 41 y 60 años entre los canteros (que iguala al de 21-40 años, rompiendo la tónica general), el menor peso del grupo de 41-60 años entre los pintores y los talladores y, finalmente, la relativa importancia de los mayores de 60 años en las artes de platería y escultura.

También muy significativa parece la media de edad aproximada de cada oficio:

\begin{tabular}{lccc}
\hline & OFICIALES & MAESTROS & MEDIA OFICIO \\
\hline Carpinteros: & 34 años & 44 años & 38 años \\
Plateros: & 38 años & 48 años & 42 años \\
Canteros: & 41 años & 45 años & 42 años \\
Pintores: & 37 años & 35 años & 35 años \\
Doradores: & 32 años & 39 años & 34 años \\
Talladores: & 38 años & 47 años & 38 años \\
Escultores: & 23 años & 42 años & 41 años \\
Bordadores: & 26 años & 35 años & 31 años \\
\hline
\end{tabular}

Una diferencia de alrededor de diez años suele separar a oficiales y maestros. Las anomalías observadas son la acusada diferencia de edad entre maestros y oficiales de escultura (si bien el número de oficiales es muy reducido en este arte) y, por el contrario, la escasa diferencia de edad entre maestros y oficiales en los oficios de dorador, cantero y pintor. En este último caso la lógica del sistema gremial se rompe, mostrando mayor edad, aunque ligeramente, los oficiales que los maestros. En principio, puede afirmarse que las diferencias de edad son mayores en oficios de largo aprendizaje y mayor consideración artística. La excepción referida de los pintores se puede deber a la variedad de «calidades» de su oficio. 
En oficios muy especializados, como el de platero, la etapa de formación podía resultar bastante larga. Así, en el siglo XVIII, Agustín Núñez precisó veinte años de aprendizaje y oficialía antes de convertirse en maestro platero, Diego de Tarragón necesitó dieciocho años, Pedro González y Fernando de Espínola más de doce, etc... ${ }^{20}$.

La media de edad en el conjunto de cada oficio es realmente elevada entre los plateros, los canteros y los escultores, superando en los tres casos los cuarenta años. En los restantes oficios no se alcanza esa edad. Incluso la media es muy reducida entre los bordadores (31 años), tal vez por tratarse de una dedicación previa al desempeño de otro oficio.

\section{EL GREMIO COMO GRUPO: TOPOGRAFÍA, PARENTESCO Y SOLIDARIDAD.}

La tradición medieval identificaba al gremio como grupo por muchos motivos, entre los que se encontraba la ubicación de los talleres en un determinado lugar. Por ello, no parece irrelevante detenernos en los barrios en los que habitaban los que ejercían los oficios que se analizan, comparando las cifras de artesanos con la población de cada demarcación (porcentaje de la columna de la derecha), según los datos del Catastro de Ensenada ${ }^{21}$ :

\begin{tabular}{lcrc}
\hline PARROQUIA & ARTESAN. & HABIT. & $\%$ \\
\hline Sta. Ana & 12 & 1.242 & 0,96 \\
S. Andrés & 24 & 1.433 & 1,67 \\
Ntra. Sra. Angustias & 75 & 6.943 & 1,08 \\
S. Bartolomé & 1 & 238 & 0,42 \\
S. Cecilio & 5 & 1.447 & 0,34 \\
S. Cristóbal & 2 & 734 & 0,27 \\
Sta. Escolástica & 12 & 3.392 & 0,35 \\
S. Gil & 30 & 1.735 & 1,72 \\
S. Gregorio & 1 & 351 & 0,28 \\
S. lldefonso & 15 & 7.403 & 0,20 \\
S. José & 15 & 1.280 & 1,17 \\
\hline
\end{tabular}

20 Bertos herrera, Ma. P. Los escultores..., pág. 103. Considera a la platería como "uno de los oficios más completos" (ibidem, pág. 13).

${ }^{21}$ Los datos de población total de cada parroquia en SANZ SAMPELAYo, Juan. Granada en el siglo xvIII. Granada, 1980, pág. 307. 


\begin{tabular}{lcrc}
\hline PARROQUIA & ARTESAN. & HABIT. & $\%$ \\
\hline S. Juan de los Reyes & 15 & 945 & 1,58 \\
Stos. Justo y Pastor & 28 & 4.198 & 0,66 \\
S. Luis & & 1.074 & \\
Sta. María Alhambra & 2 & 481 & 0,41 \\
Sta. María Magdalena & 19 & 4.913 & 0,38 \\
S. Matías & 31 & 2.126 & 1,45 \\
S. Miguel & 26 & 990 & 2,62 \\
S. Nicolás & 8 & 799 & 1,00 \\
Stos. Pedro y Pablo & 1 & 1.060 & 0,09 \\
Sagrario & 47 & 4.173 & 1,12 \\
El Salvador & 4 & 2.785 & 0,14 \\
Santiago & 6 & 1.305 & 0,45 \\
\hline TOTAL & 379 & 51.047 & 0,74 \\
\hline
\end{tabular}

Según se desprende de los valores relativos, feligresías como $S$. Miguel, S. Andrés, S. Gil, S. Juan de los Reyes, S. Matías, S. José o el Sagrario, presentan un carácter artesanal bastante marcado. En cuanto a los valores absolutos, son siete las parroquias que superan los veinte artesanos de los oficios estudiados (Angustias, Sagrario, S. Matías, S. Gil, Stos. Justo y Pastor, S. Miguel y S. Andrés), englobando en conjunto casi el $70 \%$ del total.

Por oficios, la distribución parroquial puede resultar significativa:

- Carpinteros: dominan en las Angustias, seguida del Sagrario, Stos. Justo y Pastor y S. Gil.

- Plateros: residen principalmente en la parroquia del Sagrario ${ }^{22}$, a la que siguen las Angustias y $\mathrm{S}$. Matías.

- Canteros: el predominio de las Angustias es absoluto en este oficio.

- Pintores: la parroquia de S. Miguel, en el Albaicín, destaca sobre todas las demás.

- Talladores: sobresale especialmente la demarcación de S. Andrés.

- Escultores: aunque sin una marcada diferencia, es S. Miguel la parroquia que alberga a más miembros de este arte.

22 Zacatín, Puente del Carbón y Alcaicería fueron desde el siglo xvı los puntos de establecimiento de los talleres de platería (BERTos Herrera, Må. P. Los escuitores..., pág. 100). 
Sólo en parte coincide la ubicación de los oficios con la relatada en un poema descriptivo del año 1550: entalladores y bordadores en la demarcación de Santiago (contigua a S. Andrés); cantería en el Sagrario y «roquería» próxima a las Angustias (que aún no era parroquia); platería y joyería en la feligresía del Sagrario; carpinterías en la Magdalena y serrerías de madera a las orillas del Darro (posteriormente demarcación de las Angustias) ${ }^{23}$.

Ahora bien, si atendemos a la ubicación de los talleres, centros de producción y venta que realmente ofrecen un perfil artesanal determinado a un barrio o feligresía, sería más adecuado referirse en concreto a las casas de los maestros.

En este sentido, tan sólo en siete parroquias se cuentan diez o más maestros; en su conjunto representan al $71 \%$ de los artesanos con ese grado laboral:

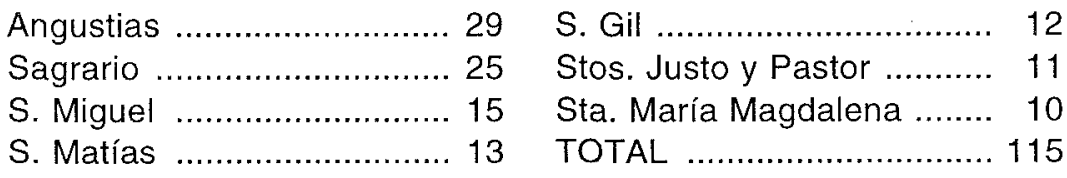

En la parroquia de las Angustias dominan los maestros carpinteros y canteros; en la del Sagrario, los maestros plateros; en S. Miguel, pintores y escultores.

En líneas generales, la Granada del siglo XVIII presenta tres áreas bien diferenciadas: la zona alta de antiguo poblamiento (Albaicín y Alhambra), la "ciudad baja» de antiguo poblamiento (S. Andrés, Santiago, S. Gil, Sta. Ana, Sagrario, S. Matías, Sta. Escolástica y S. Cecilio) y los barrios periféricos en expansión hacia la Vega (S. Ildefonso, Stos. Justo y Pastor, Sta. María Magdalena y Ntra. Sra. de las Angustias). En la primera (que alberga al $21 \%$ de la población de la ciudad) se concentra el $19,8 \%$ de los artesanos estudiados y hasta el $25,3 \%$ de los maestros; en la segunda (que supone el $33 \%$ de la población granadina), el $44,1 \%$ de los artesanos y el $42 \%$ de los maestros; en la tercera (con el $46 \%$ de la población total), tan sólo el $36,1 \%$ de los artesanos analizados y el $32,7 \%$ de los maestros.

23 "Las partidas de la gran Ciudad de Granada" de Sebastián Martínez, en Orozco PaRdo, José Luis. Christianópolis. Urbanismo y Contrarreforma en la Granada del Seiscientos. Granada, 1985, págs. 155-159. Según las ordenanzas de la ciudad, la venta de madera — de las sierras de Huéscar, Segura, Cazorla, Alhama y Almuñécar; más tarde también del Pinar del Duque y de la sierra de Gor- debía realizarse entre la Puerta del Rastro y la Puerta de Bibataubín. 
Es evidente el peso del casco antiguo en la ubicación de los talleres de estos oficios, incluso en el barrio del Albaicín, carente ya del esplendor de pasadas épocas. La topografía artesanal granadina del Setecientos continúa, por tanto, en parámetros bastante tradicionales.

En la producción artesanal del Antiguo Régimen, la familia constituye el núcleo de aprendizaje de un oficio y a veces la célula productiva. La simple reiteración de apellidos en cada uno de los oficios estudiados lo pone de manifiesto (vid. Apéndice).

En algunos casos, incluso se hace constar la presencia de hijos trabajando junto a sus padres, bien como oficiales o bien como aprendices. Algunos ejemplos ilustrarán esta realidad:

- Carpinteros: junto a Félix del Águila, oficial de 55 años, trabajaban sus hijos, también oficiales de carpintería, Diego y Juan, de 21 y 18 años respectivamente; hasta cuatro hijos (entre 20 y 24 años) del maestro carpintero Francisco Ribera trabajaban como oficiales en su taller (parroquia de las Angustias).

- Plateros: bajo la sombra del maestro Salvador de Argüeta, de 80 años de edad, trabajaban como oficiales sus dos hijos Francisco y Vicente, de 30 y 22 años respectivamente; los hermanos Diego y Salvador García auxiliaban a su padre, maestro de platería de 52 años, con taller en la parroquia del Sagrario.

En los otros oficios, los Arévalo y los Castillo formaban auténticas dinastías de canteros; igual que los Cabello y los Salmerón entre los talladores, o los Saravia entre los doradores. Algunas de estas familias resultarán casi hegemónicas en las producciones artísticas de la segunda mitad del XVIII: es el caso de Gabriel y Luis Arévalo, sobre todo éste último, en las obras de cantería, o de Alejandro Salmerón y sus hijos Juan y Francisco en la retablística y en otros elementos de las decoraciones eclesiales, al frente de estas obras desde la maestría mayor del Arzobispado.

La proximidad, cuando no concentración, de los talleres de un mismo oficio determina vínculos sociales en el seno del grupo y condiciona su asociacionismo, no sólo laboral, sino también religioso.

Es bien conocida la íntima relación de cofradías y gremios en la España del Antiguo Régimen ${ }^{24}$. De los oficios ahora analizados en el

${ }^{24}$ Vid. la obra clásica de Rumeu de ARmas, Antonio. Historia de la Previsión Social en España. Cofradias, Gremios, Hermandades, Montepios. Madrid, 1944 (reed. en Barcelona, 1981). 
ámbito granadino, dos, los más numerosos, destacan como promotores de pujantes hermandades religiosas ${ }^{25}$. De una forma $u$ otra, se incardinaban en el barrio donde se concentraban los artesanos correspondientes.

De este modo, los plateros granadinos se agrupaban en la hermandad (convertida en colegio profesional hacia $1735^{26}$ ) de S. Eloy, con sede en el convento de Ntra. Sra. de la Cabeza de carmelitas caizados, y con determinadas funciones religiosas en el convento de capuchinas (ambos en la demarcación parroquial del Sagrario). Por su parte, los carpinteros se agrupaban en la hermandad gremial de S. José, con sede en el templo parroquial del mismo nombre, aunque veneraban al santo en una tribuna ubicada en la zona de la Carpintería (parroquia de la Magdalena).

La hermandad de San Eloy presenta sus primeras reglas aprobadas por la autoridad civil en 1569. Se renovaron en 1735 , constando su aprobación por real cédula de Felipe $\mathrm{V}$. La hermandad se dotaba de un total de catorce directivos, incluyendo a dos fieles veedores ${ }^{27}$. En 1771 se actualizaron sus ordenanzas mediante real despacho concerniente al colegio de Madrid, y por extensión al resto del país ${ }^{28}$. Los plateros celebraban sus cultos a S. Eloy y a la Asunción de María ${ }^{29}$.

La hermandad de $S$. José agrupaba a los maestros de carpintería, que ingresaban en ella de forma automática al aprobar el examen de maestría. Al cabildo celebrado en enero de 1755 asistieron cincuenta y cinco maestros, es decir la mayoría de los existentes. Existía esta cofradía al menos desde 1532, fecha de la primera aprobación de sus reglas. Dedicaban cultos anuales a S. Eloy y a la Inmaculada Concepción ${ }^{30}$.

\footnotetext{
25 Sobre hermandades de oficios artísticos, vid. GUERRERO LOVILLO, J. "La capilla de los pintores de la hermandad de San Lucas", en Archivo Hispalense, XVI (1952), págs. 123-133; GaRcíA CANTús, D. El gremio de plateros de Valencia en los siglos XVIII y $x I x$. Valencia, 1985; PÉREZ SANTAMARÍA, A. "La cofradía de escultores de Barcelona durante el siglo xvil", en Academia, 65 (1987), págs. 209-244; Bertos Herrera, Ma . P. Los escuitores..., y Fernández Martín, Maa. M. "Aproximación al estudio de la hermandad de carpinteros de Cádiz durante el siglo XVIII", en Gremios, hermandades y cofradias. San Fernando, 1992, vol. I, págs. 205-214.

${ }^{26}$ Muchos oficios aspiraban a convertirse en colegios. En Barcelona los pintores lo lograron en 1682 y los plateros en 1732 (Molas RiBalta P., Los Gremios..., pág. 65).

${ }^{27}$ Vid. por extenso su organización en LÓPEz MuÑoz, Miguel Luis. Contrarreforma y cofradias en Granada. Aproximación a la historia de las cofradias y hermandades de la ciudad de Granada durante los siglos XVII y XVIII. Granada, 1992 (ed. en microfichas).

ze Bertos Herrera Ma . P. Los escultores..., pág. 127.

29 LAChICA Benavides, Antonio de. Gazetilla curiosa o Semanero granadino. Papel XLII (1765), pág. 2 vta.

30 Vid. López Muñoz, Miguel Luis. "La Hermandad de Carpinteros de San José de Granada", en Estudios Josefinos, 95 (1994), págs. 3-25.
} 
Una breve mención merece la Hermandad del Corpus Christi, establecida en el hospital del mismo nombre y con una finalidad claramente benéfica. A ella pertenecían gentes de distintos sectores sociales, incluidos algunos notables. Muchos artistas figuran en sus listas desde el siglo XVI y se sabe que algunos de ellos enriquecieron con sus obras el interior de su pequeña iglesia (llamada popularmente de los «Hospitalicos»). La fundación de esta hermandad data de 1502.

\section{EL STATUS SOCIO-ECONÓMICO A MEDIADOS DEL SIGLO XVIII}

Los ingresos percibidos por los distintos artesanos, según el Catastro, se ajustan a valores prestablecidos, lo que hace problemática su consideración como datos reales. Así, a los propietarios de fincas urbanas se les asigna una renta anual por ellas, aunque fueran (como puede desprenderse en muchas ocasiones) el lugar de residencia familiar. En cuanto a los oficios, se estipulan en la mayoría de los casos unos ingresos fijos para maestros y oficiales:

OFICIO INGRESOS ANUALES (EN REALES)

\begin{tabular}{lcc} 
& Maestros & Oficiales \\
\hline Canteros & 1.440 & 1.260 \\
Talladores & 1.260 & 900 \\
Carpinteros & 1.080 & 720 \\
Doradores & 1.080 & 720 \\
Bordadores & 720 & 540 \\
Pintores & & 540 \\
Escultores & & 540 \\
\hline
\end{tabular}

Las cantidades se obtienen estableciendo un jornal diario que se multiplica por 180 días de trabajo al año. Por ese procedimiento se fijan para los maestros: ocho reales diarios para los canteros, siete para los talladores, seis para los carpinteros y doradores, y cuatro para los bordadores. Para los oficiales, con una regulación más precisa y fija por salario, se establecen: siete reales diarios para los canteros, cinco para los talladores, cuatro para los carpinteros y doradores, y tres para los bordadores, pintores y escultores.

Aunque no se correspondan exactamente con la realidad, la misma gradación de ingresos es indicativa del poder económico de cada oficio y, por ende, de su consideración social. Pero es que además permite esta- 
blecer las diferencias económicas entre maestros y oficiales, mínima para los canteros y más acentuada en los demás oficios. A un oficial de carpintería se le regulan como ingresos $2 / 3$ de lo percibido por un maestro carpintero. La relación entre lo regulado para un oficial y para un maestro es de 1:1,5 en la carpintería y dorado, 1:1,4 en el oficio de talla, 1:1,3 en el bordado y tan sólo $1: 1,1$ en la cantería. Las diferencias no parecen excesivas, pero deben matizarse con valores reales.

El cuadro anterior está incompleto, al faltar algunas categorías y oficios. Los casos que faltan son atípicos, por la variedad de ingresos reseñados. Así, a los maestros de escultura se les regulan seis reales diarios y, en cuatro casos, ocho (Isidro González, José Ramírez de Valdivia, Torcuato Ruiz del Peral y Agustín de Vera); para los maestros pintores, los niveles de renta regulada son menores, cuatro o seis reales al día. Por la especificidad de su actividad, se regulan ingresos distintos, en el seno del arte de escultura, a Juan Luengo, maestro de «abrir láminas» (1.375 reales anuales), y a Félix Alvarado, artífice de buril (880 reales), grabadores ambos.

Como otras variables anteriores, también ésta de las rentas evidencia el carácter más avanzado, superando la rigidez gremial, de los oficios de carácter artístico. Se cotizaban más determinados maestros en razón de sus obras y fama, aunque es éste, lógicamente, un factor relativo. La demanda en un determinado ambiente devocional y artístico hacía subir la estimación de los principales artistas. Esto redundaba en sus ingresos y, a veces, en su consideración social, pero no afectaba a la rígida estructura gremial.

Las disparidades más notorias se alcanzan, sin embargo, en el arte de la platería. Los datos generales del oficio ofrecen el siguiente balance:

\begin{tabular}{lcc}
\hline PLATEROS & REALES/DIA & INGRESOS ANUALES \\
\hline 6 maestros & 12 & 2.160 \\
8 maestros & 8 & 1.440 \\
8 maestros & 6 & 1.080 \\
8 maestros & 4 & 720 \\
2 oficiales & 7 & 1.260 \\
6 oficiales & 5 & 900 \\
6 oficiales & 4 & 720 \\
\hline
\end{tabular}

La variedad puede responder principalmente a las circunstancias que rodean el trabajo del platero, como es el elevado valor de la materia prima empleada. La cantidad de piezas de plata acumuladas en las tiendas-taller puede ser decisiva en la elaboración de esa gradación que, además de su 
variado abanico en el canon aplicado, denota cierta relatividad económica en relación al grado profesional.

En cualquier caso, los datos de personal producible añaden nuevos matices a los ingresos, pues además de computar lo ingresado en concepto de trabajo, recoge las rentas procedentes de casas, tierras, tiendas, etc... Con esos datos, la aproximación a la realidad económica de los dintintos artesanos es mayor y, como cabía esperar, denota desigualdades más acusadas que las establecidas por los baremos de los oficios en sus distintos grados. Con esos datos se ha elaborado el siguiente cuadro general:

\begin{tabular}{lccr}
\hline OFICIO & No. PERSON & ING. TOTALES & MEDIA \\
\hline Carpinteros & 120 & 108.971 & 908,09 \\
Plateros & 34 & 56.331 & $1.656,79$ \\
Canteros & 41 & 61.685 & $1.504,51$ \\
Pintores & 31 & 25.800 & 832,25 \\
Doradores & 18 & 23.714 & $1.317,44$ \\
Talladores & 17 & 17.460 & $1.027,05$ \\
Escultores & 15 & 18.108 & $1.207,20$ \\
Bordadores & 5 & 2.520 & 630,00 \\
\hline TOTAL & 281 & 314.589 & $1.119,53$ \\
\hline
\end{tabular}

Con él se comprueba que el escalón inferior entre los oficios objeto de análisis corresponde a los bordadores, seguidos a gran distancia por pintores y carpinteros. Los estratos económicamente más elevados se reservan a los plateros, canteros y doradores. Los plateros duplican la renta de los pintores y casi también la de los carpinteros. Las diferencias económicas entre oficios pueden resultar acusadas. Los valores extremos alcanzan la proporción 1:2,6 (de bordadores a plateros).

Pero quizás lo más significativo que deja traslucir el Catastro no sean las diferencias de renta entre unos y otros oficios, sino la realidad reglamentista de la organización gremial, que homogeneizaba el nivel de vida de los artesanos de un mismo oficio, con distinción lógicamente de grados. Las limitaciones de precios y salarios, las cuotas de producción y las exigencias técnicas igualaban la labor de los artesanos. Las ayudas asistenciales, en conyunturas determinadas, cooperaban a mantener el status económico del agremiado.

Las ordenanzas de los carpinteros de Granada establecían, por ejemplo, "que si algún oficial cayere malo le den todo lo que huviere menester, así de físicos, como de medicinas, hasta tanto que sea sano. Esto se 
entienda siendo pobre y no siendo mal de bubas o de cuchilladas, y si muriere de lo sepultar y hazer enterrar» ${ }^{31}$.

Mayor especificación se encuentra en las ordenanzas del colegio de San Eloy de plateros de Granada en caso de enfermedad: "que se le lleve promptamente del caudal que exista en el arca y si se le agravare la enfermedad, deverán los referidos elegir cada día dos mancebos de este arte para que le asistan uno de día y otro de noche, hasta que se mejore, pero si el tal artífice platero muriere de la espresada enfermedad sin tener medios algunos para enterrarse, se subministre del caudal del arca a este fin» ${ }^{32}$.

Del conjunto de 281 artistas y artesanos cuya situación económica es conocida ${ }^{33}$, hemos extraído los veinticinco que superan los 1.500 reales de ingresos anuales (una vez restados a los datos del Catastro las cargas de las fincas de su propiedad y los ingresos de hijos $u$ otros miembros de la familia a su cargo). Las cifras se presentan en reales:

\section{INGRESOS MEDIOS ANUALES EN LOS DISTINTOS OFICIOS (según el Catastro de Ensenada)}

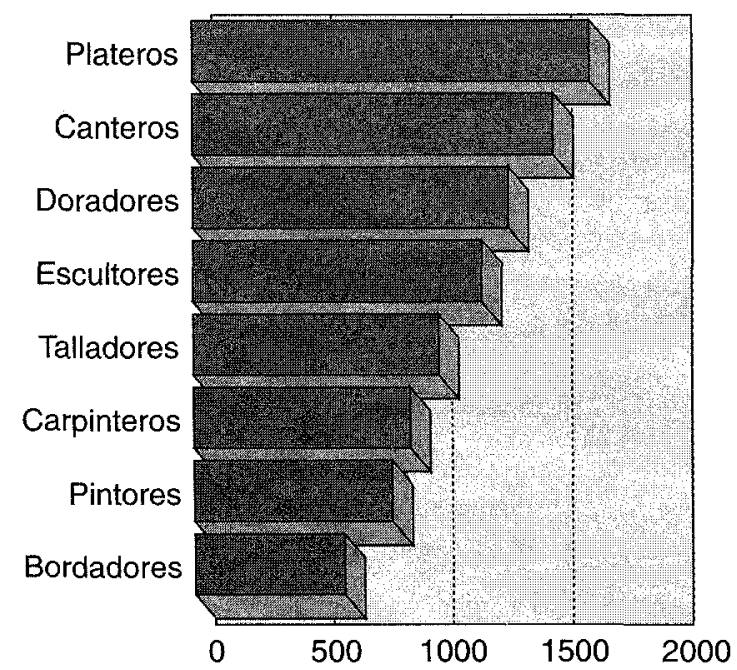

Media anual (reales)

Ordenanzas..., fol. 176.

B.N., Manuscritos, 7554 (ordenanzas de 1735).

${ }_{33}$ No se incluyen aquí los pertenecientes al estado religioso como Alfonso del Castillo, José Francisco Guerrero o el cartujo fray José Manuel Vázquez. 


\begin{tabular}{lccc}
\hline NOMBRE, OFICIO Y GRADO & ING. TOT. & \%OFICIO & $\%$ \%ESTO \\
\hline Francisco Navarro Rivero, maestro & & & \\
$\quad$ dorador & 8.003 & 13,5 & 86,5 \\
José de Bustos, maestro platero & 5.854 & 36,9 & 63,1 \\
José de Bada, maestro cantero & 4.977 & 88,4 & 11,6 \\
Jerónimo de Palma, maestro de obras & & & \\
$\quad$ de Granada & 4.297 & 76,8 & 23,2 \\
Juan de Balaguer, maestro platero & 3.640 & 39,6 & 60,4 \\
Tomás Ruiz del Río, maestro platero & 3.031 & 71,3 & 28,7 \\
José de Domedel, maestro platero & 2.920 & 24,7 & 75,3 \\
Tomás J. González Orejudo, maestro & & & \\
platero & 2.655 & 81,4 & 18,6 \\
Manuel Tene, maestro platero & 2.352 & 91,8 & 8,2 \\
Benito Pérez, maestro platero & 2.304 & 70,3 & 29,7 \\
Alejandro Padilla, maestro platero & 2.160 & 100,0 & \\
Lorenzo Solano, maestro platero & 2.160 & 100,0 & \\
Agustín de Vera, maestro escultor & 2.100 & 68,5 & 31,5 \\
Agustín de Arias, oficial cantero & 1.990 & 63,3 & 36,7 \\
Juan Enríquez, maestro platero & 1.950 & 83,1 & 16,9 \\
Francisco Román, maestro pintor & 1.940 & 55,7 & 44,3 \\
Felipe Lechuga, maestro platero & 1.916 & 57,4 & 42,6 \\
José de Flores, maestro carpintero & 1.876 & 57,5 & 42,5 \\
Juan Rodríguez, maestro cantero & 1.811 & 79,5 & 20,5 \\
Dionisio del Villar, maestro cantero & 1.696 & 84,9 & 15,1 \\
Juan Román, oficial carpintero & 1.671 & 43,1 & 56,9 \\
Torcuato Ruiz del Peral, maestro & & & \\
escultor & 1.637 & 88,0 & 12,0 \\
José R. Ramírez de Valdivia, maestro & & & \\
escultor & 1.634 & 88,1 & 11,9 \\
Salvador de León, maestro cantero & 1.581 & 91,1 & 8,9 \\
Isidro González, maestro escultor & 1.546 & 93,1 & 6,9 \\
\hline
\end{tabular}

Once plateros se incluyen entre las veinticinco personas enumeradas, lo que confirma el alto nivel de renta de este grupo profesional, seguido de los canteros (seis) y de los escultores (cuatro). La presencia de otros oficios es excepcional: dos carpinteros, un pintor y un dorador, pese a lo llamativo de este último caso. Ausencia absoluta de talladores y bordadores. Obsérvese también el predominio lógico de los maestros, con la excepción de dos oficiales, uno que a su elevada remuneración como cantero (1.260 reales) unía la explotación de una tienda y otro que completaba su salario con rendimientos de ganadería. 
En general, lo ingresado por el ejercicio del oficio suele ser fundamental en la composición de la renta personal. Esa partida alcanza su máximo en los 2.160 reales anuales de algunos plateros (Bustos, Ruiz del Río, González Orejudo, el fiel del contraste y marcador Tene, Padilla y Solano). Le superan en las rentas de su oficio, sólo dos maestros de cantería, bien asalariados por el desempeño de empleos públicos: 3.300 reales anuales para Jerónimo de Palma por su cargo de maestro mayor de obras de Granada ${ }^{34}$ y hasta 4.400 reales anuales para José de Bada como maestro mayor de la Catedral granadina ${ }^{35}$.

Sólo en cinco casos los ingresos no provenientes del oficio superan el $50 \%$ de la renta del individuo. Se trata del producto de casas, tierras y ganado (Francisco Navarro Rivero, Juan Román) o del desempeño de otros empleos: administrador de patronatos y de un convento (José de Bustos), rey de armas de la Capilla Real (Juan de Balaguer) y portero del mismo templo (José de Domedel, más dedicado a esta portería que a la platería).

En los restantes casos, los ingresos complementarios provienen de rentas de fincas urbanas $y$, raramente, rústicas, tiendas de pan o hilos (Agustín de Arias y Juan Rodríguez, respectivamente) ${ }^{36}$, ganado o incluso una tahona de aceite (Francisco Román).

En algunos oficios, por tanto, se encuentran personajes acomodados, gracias a ingresos al margen del oficio. También se ha constatado esta realidad entre algunos maestros de albañilería (oficio en que se observan acusadas desigualdades económicas: 1.440 reales anuales para los maestros, 900 para los oficiales y 540 para los peones). Así, el maestro albañil José Sánchez del Olmo duplicaba el producto regulado para su oficio, gracias a los ingresos de otro oficio, de una tienda y de algunas casas, alcanzando los 3.143 reales anuales. Hasta 10.683 reales se elevan los ingresos de otro maestro albañil, Juan José Fernández Bravo, en virtud de la explotación de ganado (especialmente mulas) y de tierras, posesión de

34 Aunque lo estudiamos aquí por el cargo público que ostentaba, pertenecia al arte de la albañilería, con el grado de maestro. A su muerte se mandó enterrar en la capilla de la Virgen de la Asunción de la iglesia de Santiago, propia de este arte (Archivo del Instituto Gómez-Moreno, leg. CXIII, fols. 168-169).

${ }_{35}$ En el año 1722 José de Bada fue nombrado maestro mayor de las catedrales de Granada y Málaga con pocos meses de diferencia. Con respecto a sus ingresos, baste decir que en 1744 llegó a ganar por la maestría de Málaga hasta más de doce mil reales (ISLA MINGORANCE, E. José de Bada..., págs. 54-55).

${ }_{36}$ Una de las fórmulas más comunes de pluriempleo de los artesanos era ésta de la posesión de tiendas y tabernas. Era una vía de salida a las difultades económicas de ciertos gremios; pero a la vez, contribuyó a la formación de la nueva sociedad burguesa (MOLAS RIBALTA, P., Los Gremios..., pág. 119). 
casas y rentas de una calera y de un almacén de madera ${ }^{37}$. Se trata de un caso claro de maestro de obras, con inversiones en diversos negocios relacionados con la actividad inmobiliaria o incluso especulativa.

El análisis de las rentas en el seno de un oficio determinado puede resultar revelador. Elegimos el arte de escultura, muy aprehensible por su tamaño reducido ${ }^{38}$ y con un perfil artístico muy marcado. He aquí sus datos (expresados en reales):

\begin{tabular}{lcccc}
\hline NOMBRE Y CATEGORIA & EDAD & OFICIO & CASAS & INGRE. \\
\hline Agustín de Vera, maestro & 53 & 1.440 & 660 & 2.100 \\
Torcuato Ruiz, maestro & 42 & 1.440 & 197 & 1.637 \\
José R. Ramírez, maestro & 53 & 1.440 & 194 & 1.634 \\
Isidro González, maestro & 40 & 1.440 & 106 & 1.546 \\
Juan Luengo, maes. grabador & 67 & 1.375 & & 1.375 \\
Diego Sánchez, maestro & 48 & 1.080 & 174 & 1.254 \\
Martín Santisteban, maestro & 39 & 1.080 & 120 & 1.200 \\
José Hurtado, maestro & 30 & 1.080 & & 1.080 \\
Blas Moreno, maestro & 36 & 1.080 & & 1.080 \\
José Palacios, maestro & 40 & 1.080 & & 1.080 \\
Juan de Salazar, maestro & 34 & 1.080 & & 1.080 \\
Pedro Tomás Valero, maestro & 36 & 1.080 & & 1.080 \\
Félix Alvarado, maes. buril & 33 & 880 & & 880 \\
Antonio González, oficial & 27 & 540 & & 540 \\
Bernardo de Vera, oficial & 20 & 540 & & 540 \\
\hline
\end{tabular}

Con facilidad se observa que los escultores vivían fundamentalmente del trabajo de sus manos, incluso uno de condición hidalga como José R. Ramírez de Valdivia. Aunque a Agustín de Vera se le reconoce la posesión de un oficio de receptor del número, en el momento de la encuesta catastral el oficio se hallaba secuestrado.

Por lo demás, sólo la renta de fincas urbanas puede añadirse a los ingresos de los escultores. $Y$ ello en muy pocos casos, dado que el Catastro incluye, con una renta estimativa, la vivienda habitual de cada artesano.

${ }^{37}$ Ambos casos en A.R.Ch.G., Catastro, lib. 320. Fernández Bravo llegó a ser, poco después de la encuesta, maestro mayor de obras del Arzobispado y de la Alhambra.

${ }_{38}$ No fue muy extenso en otros lugares. La cofradía de escultores de Barcelona agrupaba a 12 miembros en 1741, aunque el número subió hasta 33 cuarenta años más tarde (PÉREZ Santamaria, A., «La cofradía de escuitores...", pág. 213). Recuérdese que en Granada el Catastro incluye en este arte a dos grabadores. 
De ahí que sólo puedan computarse auténticos ingresos por este concepto a Agustín de Vera y a José R. Ramírez, propietarios de cuatro y dos casas, respectivamente. En aquellos casos, abundantes, en que no se consigna casa alguna, debe pensarse que el artista vivía en la casa paterna (Bernardo de Vera) o que habitaba algún inmueble en alquiler.

Entre los propietarios de casas sólo uno no alcanza los cuarenta años. Por el contrario, entre los no propietarios, sólo uno alcanza los cuarenta años. La edad, por tanto, es un factor incidente en el nivel de riqueza.

Para comprender mejor el nivel de vida de esos artistas habría que considerar también la realidad familiar. No es lo mismo tener a su cargo una (José Palacios) o dos personas (José R. Ramírez, Antonio González de la Peña), que cinco (Agustín de Vera, Isidro González), seis (Pedro T. Valero), siete (Juan de Salazar) e incluso nueve (Martín Santisteban).

En todo caso, los cuatro primeros maestros de la tabla anterior componían la «élite» del arte de la escultura a mediados de la centuria, con Agustín de Vera y Ruiz del Peral a la cabeza. De los restantes, algunos alcanzaron cierto renombre en fechas más tardías (Pedro Tomás Valero, Blas Moreno).

\section{CONCLUSIONES.}

Las páginas precedentes han tratado de ofrecer una visión sintética de la situación laboral y socio-económica de distintos oficios de la Granada del siglo XVIII que hoy consideraríamos artísticos. En un primer acercamiento a la fuente catastral, se ha realizado una selección de oficios y datos y una posterior sistematización de los mismos.

La simple cuantificación de los datos catastrales, así como la rigidez y poca matización de los mismos en materia gremial o económica, enmascaran en plano de igualdad personalidades bien diferentes y de diversa valía artística, que no parecen destacar en la homogeneidad de los oficios. Aquí se encuentran Juan Luengo, el más importante grabador de la centuria; José de Bada, de la progenie de canteros-arquitectos, cuya obra constituye un hito singular en la arquitectura dieciochista granadina; o los epígonos de la escuela barroca de escultura, último aliento de cierta importancia de una más que estimable tradición artística, representados por escultores como Torcuato Ruiz del Peral o Agustín de Vera Moreno, con el cultivo ya no sólo de la madera, sino también de la piedra.

Ahora bien, la utilización de los datos del Catastro de Ensenada permiten sólo una labor de aproximación. La consulta sistemática de otras fuentes documentales, de los libros parroquiales para la reconstrucción de 
familias, de la documentación notarial (el camino más difícil, sin duda) para el análisis de escrituras de propiedad, testamentos e incluso contrataciones de obras artísticas, de documentos judiciales que dejen traslucir a través de los pleitos la consideración social de los artistas, o de fuentes municipales que nos informen de los exámenes de los oficios, de tasaciones y licencias para tiendas y talleres, permitirá profundizar en el análisis social de los artistas, en sus posibilidades de promoción, en su proyección artística a través de talleres, en los gestos de solidaridad entre ellos.

En cualquier caso, los datos recogidos en el Catastro ofrecen indudablemente una visión de conjunto; en este sentido, se adjunta en forma de Apéndice una relación de los artesanos o artistas pertenecientes a los oficios objeto de nuestra atención. Además, la información catastral deja traslucir en esas actividades una estructura gremial, con sus connotaciones de rigidez y control.

No obstante, hay diversos indicios para pensar que el talento artístico se traducía en un factor de alteración de la homogeneidad de la realidad gremial. El reconocimiento de diversas categorías económicas entre los maestros de ciertos oficios (platería, escultura, pintura), la juventud de los maestros en algunas artes (como la pintura), su abundancia en otras (escultura), la competencia foránea en oficios como el bordado, la existencia de maestros «desclasados», obligados a trabajar como oficiales,... son realidades que abundan en esa idea.

También lo son la presencia de algún hidalgo entre los artistas, la capacidad de ahorro e inversión de fondos en otros negocios y la consecuente mejora del nivel de vida de algunos artesanos, o la organización cuasi-empresarial de oficios como el de cantería ${ }^{39}$. A la vez, muchos artesanos, con el lucro personal como móvil, comienzan a burlar las estrictas normas del gremio, aunque sin dejar de pertenecer a él. Se sirven de él en función de sus intereses personales y no de los intereses colectivos.

En la medida en que tales indicios sean capaces de variar la concepción de la obra de arte mediante la libertad de mercado y la progresiva introducción de la ley de la oferta y la demanda en la producción y comercio de objetos artísticos ${ }^{40}$, podremos afirmar la tendencia a la superación de

38 «El moderno empresariado se formó como grupo social precisamente en el siglo XVIıl. Es indudable que, en buena parte, se nutrió con personas procedentes de las corporaciones de oficios" (MOLAS RIBALTA, P., Los Gremios..., p. 198).

${ }_{40}$ «Quien más tiene más ofrece y está en condiciones de vencer. El artista se deja querer y empieza a tener conciencia de que puede exigir. A las facilidades del cliente, el artista ofrece la corriente favorable de su fama que iba bien a su empresa" (MARTín GonzÁLEZ, Juan José. El artista en la sociedad española del siglo xVII. Madrid, 1984, pág. 206). 
unas estructuras socio-laborales que ya muchos pensadores consideraban obsoletas y contraproducentes (las medidas reformistas de 1772 y 1798 se dirigieron a liberalizar la actividad artesanal). En los oficios analizados estaríamos en el paso decisivo del artesano al artista, tal y como se concibe en la época contemporánea.

Esa etapa de tránsito, de cambio de consideración y por tanto de mentalidad, había comenzado mucho antes. En su análisis del siglo XVII afirma Martín González: «Procurarse el bienestar económico fue tarea común; pero la cuestión es determinar qué oportunidades se les brindaban. Es evidente que la primera de todas es la percepción de ingresos más elevados que otros miembros de la rama de arte que cultivaban. En este sentido cabe observar que los precios se hallan en proporción al talento" ${ }^{41}$. Junto al dinero, los artistas más célebres comenzaron a aspirar a títulos y distinciones, a exenciones tributarias, a enlaces con los sectores privilegiados de la sociedad.

En el marco de las iniciativas artísticas, y sus funciones y significados, no sólo en Granada, sino en todo el país, late la lucha intelectualista por la nobleza y libertad («ingenuidad») del arte. La centuria precedente ya conoce un proceso de reivindicación profesional de los artistas. Uno de sus principales fines era, obviamente, la exención de cargas sociales, especialmente el repartimiento de soldados y las alcabalas. Abanderados de dicho proceso serán los pintores a través de múltiples pleitos ${ }^{42}$.

Pero no era éste el fin único, sino que cuentan también la ambición personal, la aspiración de prestigio profesional y de privilegio social. Ello explica los esfuerzos de muchos artistas por alcanzar la condición de «artistas de cámara» o "del Rey» (a veces con remuneración, otras sin ella), la multiplicación de lazos con la jerarquía eclesiástica y la nobleza, o el desempeño de cargos públicos. Unido a esto estaba la búsqueda de la estabilidad y prosperidad económicas, que justifica muchos de estos comportamientos sociales, asi como la diversificación de actividades productivas (tiendas, almacenes, canteras ...).

El proceso se desgrana en numerosos conflictos en torno al problema del estatuto social del artista, que desarrollan planteamientos historicistas

\footnotetext{
41 Ibidem, pág. 196.

42 Documentación sobre estos pleitos y escritos en defensa de la ingenuidad de la pintura en Calvo Serraller, Francisco. La teoría de la pintura del Siglo de Oro. Madrid, 1981. De todos modos, los intereses económicos suponían un desprecio social de la profesión en los pleitos.
} 
de bases humanistas y postulados neplatónicos ${ }^{43}$. Ya Alonso Cano había sido en el Seiscientos mantenedor de una definición intelectualista de la creación artística, que llevaba a la defensa de un estatuto social consecuente. En esta línea, Palomino distingue en su Museo pictórico y escala óptica la "ciencia», como un "hábito del entendimiento, adquirido por demostración», del «arte», una segura y recta razón de las obras factibles». En este último campo, el pintor de Bujalance distingue las «artes liberales", donde los actos especulativos prevalecen sobre los actos prácticos u operaciones corporales, y las «mecánicas o fabriles», "donde las operaciones corporales superan a los actos especulativos» ${ }^{44}$.

Estas indagaciones, sin embargo, debian servir a un trabajo plenamente comprometido con las ideas contrarreformistas a través de una praxis artística de profundo emocionalismo retórico, con usos monumentales y rituales de raíz espiritualista inequívocamente religiosa.

Pero no conviene engañarse; en el caso granadino son simplemente indicios de cambio y no se observan en todos los oficios analizados. La ciudad de Granada en el siglo XVIII no presentaba un marco tan amplio para la producción artística que permitiera, como la corte, ejemplos acabados de valoración social del «artista» por el hecho de serlo. De acuerdo con lo anteriormente señalado, en Granada los talleres debieron ser muy reducidos en personal y con una demanda muy específica. La mayor parte de la producción artística granadina tenía como destino los sectores privilegiados de la sociedad y de forma especial la Iglesia diocesana y las órdenes religiosas. Ello limitaba cuantitativa y cualitativamente la labor del artista.

El desarrollo de las iniciativas artísticas en la Granada del XVIII se caracteriza por la escasa originalidad en la proyectiva arquitectónica. En los dos primeros tercios del Setecientos las iniciativas tienden a completar los programas contrarreformistas que definen a la ciudad como complejo ritual sacro, junto a escasas intervenciones de carácter civil. Son iniciativas presididas por el decorativismo como principal innovación, limitándose, por lo general, a intervenciones de carácter parcial, completivas o renovadoras (camarines, sacristías, tabernáculos, retablos) en fundaciones religiosas anteriores que quedan plenamente consolidadas en el clima contrarreformista. Las principales realizaciones en esta línea son la decoración setecentista de la catedral, el Sagrario de la misma, la sacristía y sagrario

43 Henares CuÉllar, Ignacio, "La escultura...», págs. 25 y ss. Para el siglo XVIII vid. BeLda Navarro, Cristóbal. La ingenuidad de las Artes en la España del siglo xvil. Murcia, 1993.

${ }_{44}$ Palomino y Velasco, Antonio Acisclo. El Museo pictórico y Escala óptica. Ed. de Madrid, Aguilar, 1947, págs. 129-130. 
cartujanos, los camarines de las Vírgenes de las Angustias y del Rosario, la iglesia de $\mathrm{S}$. Juan de Dios y algunos retablos y decoraciones de capillas.

En este contexto, la política ilustrada de debilitamiento de la institución gremial benefició a determinadas actividades consideradas más «nobles»: «Las profesiones liberales - boticarios, cirujanos-y los artistas -escultores, pintores - sufrieron un proceso de depuración en el que perdieron las caracteristicas de artesanos. Algunas profesiones se convirtieron en carreras universitarias, con un plan de estudios y Academias de rango oficial (Farmacia, Cirujía, Bellas Artes), gracias a la política de los ministros ilustrados» ${ }^{45}$.

En sus desarrollos setecentistas más tardíos, esta tendencia se encuentra próxima a liquidar la fraternidad gremial. La Real Cédula de $1^{\circ}$ de mayo de 1785 ordena en todo el reino la entera libertad de las nobles artes del dibujo, pintura, escultura, arquitectura y grabado, sin pertenencia a gremio o colegio. La pertenencia al gremio, previa suficiencia de maestría, "en el siglo XVIII resultaba una anacrónica cortapisa en el ejercicio de un arte de hombres libres. $Y$, al mismo tiempo que se permitió pintar sin pertenecer a ningún gremio, igualmente se permitió al escultor el que dorase sus propias tallas, aunque no fuera del gremio de doradores, con otras medidas de este tenor" "46. Las medidas propuestas por la Academia de S. Fernando buscaban rendir la resistencia artesanal. La lucha por conseguir la libertad del arte y la independencia del artista era una lucha contra las corporaciones, empresa paralela a la imposición de lo neoclásico sobre lo tardobarroco ${ }^{47}$.

Asistimos, pues, al desdibujamiento de las fronteras de las artes liberales en el Setecientos. Jovellanos en el "Informe que dio a la Junta General de Comercio y Moneda sobre el libre ejercicio de las Artes» en 1785 , empleaba la palabra «arte» como "oficio» y «artista» con la equivalencia de "oficial» o "artesano". Y es que el fin era otro: le preocupaba la «libertad de las Artes", esto es, destrabar su ejercicio arremetiendo contra los gremios. Para Jovellanos, en el XVII se pedían alcabalas de las pinturas por «la confusión de las artes nobles con las mecánicas (...), por culpa de los pintores del siglo XVII que, por un lado, creían en la fuerza de su genio $y$, por otro, ejercían su arte como una profesión mecánica y servil»»48.

45 Molas Ribalta, P., Los Gremios..., pág. 215.

4o Gallego, Julián. El pintor de artesano a artista. Granada, 1976, pág. 201.

47 BÉDAT, Claude. L'Académie des Beaux-Arts de Madrid. 1744-1808. Contribution à l'étude des influences stylistiques et de la mentalité artistique de l'Espagne du xvili siècle. Toulouse, 1974 , págs. 293 y $5 s$.

4B Gallego, Julián, El pintor..., pág. 204. 
En 1752 se inaugura la Academia de S. Fernando, culminando los trabajos de la junta preparatoria creada por Felipe $V$ en 1744; desde ese momento, en ésta y en el resto de academias que se van fundando, se usa el término de «profesor». Los «profesores» serán hombres virtuosos, siendo la virtud condición indispensable para reconocer la dignidad de este arte, sin depender ya de la actividad física, reconocida como meritoria en este siglo XVIII ${ }^{49}$.

Pero la realidad entre nosotros es bien distinta. Estos valores se diluyen en su expansión hacia la periferia peninsular. El aferramiento a las formas tradicionales de la producción artística, tanto en su praxis como en su forma, en lo que tiene mucho que ver el apego popular a las devociones tradicionales y las escasas iniciativas de renovación, condiciona gravemente una profundización en las nuevas consideraciones que desde mediados de siglo se intenta imponer. El grueso de su acción e influencia vendrá después y su éxito es discutible. Pero en el momento de realización de las encuestas del catastro el esquema socio-económico obtenido, lo venimos demostrando, es plenamente tradicional. En él se diluyen los verdaderos artistas entre rigideces corporativas que, sin duda, en más de una ocasión pudieron abortar una renovación que tampoco obtuvo demasiados impulsos ajenos a las estructuras de oficios: la clientela era igualmente tradicional.

Parece evidente, pues, que estos artistas o artesanos vivían, por lo general, del fruto de su trabajo y, aunque factores como la categoría profesional o la edad y sobre todo el patrimonio personal (probablemente heredado), establecian diferencias económicas entre ellos, las más acusadas derivaban del desempeño de ciertos empleos relacionados con su actividad, bien del gremio (como alarife, alamín, fiel del contraste...), bien de la ciudad o de la iglesia (maestría mayor de obras del ayuntamiento o de la catedral).

Los miembros de los gremios representaban, por último, a sectores dinámicos de la economía urbana. Así se desprende de su capacidad fiscal, especialmente en los tributos recaudados mediante encabezamiento, o de su cooperación en todas las celebraciones de la ciudad (proclamaciones reales, fiestas del Corpus Christi, etc...). Sólo tímidamente, sin embargo,

49 Ya en la centuria anterior se usó esporádicamente el término «profesor» en sentido admiratorio y dignificante. La fuente catastral nos presenta en una ocasión a D. José Ramírez de Valdivia como "profesor del arte de la escultura»; ésta debió ser, sin duda, la respuesta del interesado - seguramente a causa de su condición hidalga-, fielmente recogida por el encuestador, si bien en el resumen general ya aparece «homogeneizado" como maestro escultor. 
lograban integrarse en el patriciado urbano, compuesto por pequeños nobles y caballeros, altos cargos de la administración, letrados y algunos poderosos comerciantes. En esa estrategia se inscribe la defensa por parte de los plateros de su posibilidad de acceso a cargos municipales ${ }^{50}$.

De este modo, parece claro que en el momento de realizarse el catastro la relativa consideración social y prosperidad económica que los artistas de mayor consideración podían llegar a alcanzar se enmarcaba siempre en el rígido marco de unas condiciones de producción y una normativa fiscal que en nada favorecía la libertad y renovación de las artes, sino que seguía demostrando la vigencia de los esquemas tradicionales en los que las estructuras gremiales desempeñaban un papel protagonista.

\section{APÉNDICE}

\section{Censo de artistas y artesanos según el Catastro de Ensenada}

$\mathrm{m}=$ maestro, $\mathrm{o}=$ oficial, $\mathrm{a}=$ aprendiz

Agrás, Antonio de: bordador (m) Águila, Diego del: carpintero (o) Águila, Félix del: carpintero (o) Águila, Juan del: carpintero (o) Aguilera, Blas Crisóstomo de: platero (m) Aguilera, Juan de: platero (m)

Ahumada Cepeda, Manuel de: platero (m) Alarcón, Francisco de: carpintero (m) Almena, Baltasar de: platero (o) Alvarado López, Félix: artífice de buril (m) Álvarez, José: pintor (m)

Aranda, Agustín de: carpintero (m) Aranda, Francisco de: dorador (m) Aranda, Juan de: cantero (m) Aranda, Miguel de: dorador (m) Arauz, Juan Francisco: pintor $(0)$ Arévalo, Gabriel de: cantero (o) Arévalo, Luis de: cantero (m) Argüeta, Francisco de: platero (o) Argüeta, Salvador de: platero (m)
Argüeta, Vicente de: platero (o) Arias, Agustín de: cantero (o) Arias, Francisco: tallador (o) Ayuso, Pedro de: pintor (o) Bada, Francisco de: cantero (a) Bada, José de: maestro mayor de obras de la Catedral (m)

Balaguer, Juan de: platero $(\mathrm{m})$ Balaguer, Manuel de: platero (o) Ballesteros, Alfonso: tallador (o) Barba, Juan de la: carpintero (o) Baullón, Francisco: platero (o) Bellido, Antonio: carpintero (o) Benavides, Francisco: pintor (o) Benet, José: carpintero (o) Benítez, Julián: cantero (o) Bosque, José del: carpintero (m) Bosque, Juan del: carpintero $(\mathrm{m})$ Bueso, Mateo: cantero (o) Bustillo, Manuel de: tallador (a)

50 En 1741 recurría la Hermandad de S. Eloy ante el rey amparando a un platero; recordaba que anteriormente «se (h)avía declarado no obstar para la obtención de dichos oficios (h)onoríficos el usar o haver usado el arte de platería” (A.R.Ch.G., 304-557-11). 
Bustos, José de: platero (m)

Cabello, Antonio: tallador (o)

Cabello, José: tallador (o)

Cabot, José Jaime: carpintero (o)

Cabra, Pedro de: pintor (o)

Calero, Alfonso: pintor $(\mathrm{m})$

Calixto, Antonio: carpintero $(\mathrm{m})$

Calvache, Pedro: bordador $(\mathrm{m})$

Calzado, Francisco: pintor (o)

Campos, Juan de: platero $(\mathrm{m})$

Canales, Diego: carpintero $(m)$

Cano, Diego: platero (o)

Cano, Gregorio: carpintero (m)

Cano, Luis: batidor/tirador de oro (o)

Cañizares, Diego: carpintero (o)

Capacho, Pedro: tallador (o)

Cárdenas, Lucas de: cantero (o)

Carmona, José de: platero (o)

Carmona, Juan de: platero (o)

Carmona, Salvador de: carpintero $(\mathrm{m})$

Carrera, Francisco: carpintero (o)

Carrillo, José: bruñidor de piedra

Carrión, Juan: pintor (m)

Castellanos, Francisco: carpintero (alarife)

Castellanos, Juan: bruñidor de piedra (o)

Castillo, Antonio del: carpintero (o)

Castillo, Francisco del: carpintero (o)

Castillo, Juan del: cantero (o)

Castillo, Juan del: cantero (o)

Castillo, Nicolás del: cantero (o)

Castro, Antonio de: carpintero

Coello, Juan: pintor

Corral, Simón del: carpintero (o)

Cuenca, Bernardo de: carpintero (o)

Cuetos, Julián de: pintor de lo basto

Chica, Jerónimo de la: pintor ( $m$ )

Chica, Roque de la: carpintero (o)

Delgado, Juan: cantero (o)

Díaz, Diego: platero $(\mathrm{m})$

Díaz, Francisco: cantero (o)

Díaz de los Reyes, Marcos: carpintero (m)

Díaz de los Reyes, Vicente: carpintero $(m)$

Dios y Ayuda, Mateo de: carpintero (m)

Domedel, José de: platero $(\mathrm{m})$

Enríquez, Juan: tirador de plata (m)

Enríquez, Luis: platero (m)

Espejo, Francisco de: carpintero (m)

Espejo Hurtado, Alfonso: cantero (o)

Federico, Bartolomé: tirador de plata (o)

Fernández, Francisco: carpintero (a)
Fernández, José: carpintero (o)

Fernández, Juan: cantero (o)

Fernández, Juan: carpintero (o)

Fernández, Roque: cantero (o)

Fernández Monzón, Joaquín: platero (o)

Ferreiros, Andrés: cantero (o)

Ferrer, Tomás: pintor (m)

Flores, José de: carpintero $(\mathrm{m})$

Flores, José de: carpintero $(\mathrm{m})$

Flores, Juan de: carpintero (a)

Fuente, Antonio de la: carpintero $(\mathrm{m})$

Fuente, Francisco de la: cantero (o)

Fuente, José de la: carpintero $(\mathrm{m})$

Fuente, Nicolás de la: tallador $(\mathrm{m})$

Gamarra, Manuel: platero (m)

Gamarra, Pedro: platero (m)

Gamarra, Tomás: platero $(\mathrm{m})$

Gaona, Francisco: platero (m)

Gaona, Pedro: carpintero (m)

García, Bartolomé: cantero (o)

Garcia, Bernardo: pintor (o)

Garcia, Cristóbal: carpintero (o)

García, Diego: platero (o)

García, Gabriel José: carpintero (m)

Garcia, Gregorio: carpintero (m)

Garcia, Juan: carpintero (m)

García, Lorenzo: cantero (o)

García, Salvador: platero (o)

García, Salvador: vaciador de plata $(\mathrm{m})$

García, Vicente: carpintero (m)

Garcia del Castillo, Sebastián: carpintero (m)

Garzón, Diego: carpintero (o)

Girela, Manuel de: carpintero (o)

Gómez, Juan: carpintero (m)

González, Gabriel: platero (o)

González, Francisco: carpintero (o)

González, Francisco: carpintero (o)

González, Isidro: escultor (m)

González, Juan José: carpintero (m)

González, Lorenzo: carpintero (o)

González, Manuel: carpintero (m)

González, Miguel: carpintero (m)

González Borrego, Miguel: bordador (o)

González Orejudo, Tomás: platero (m)

González de la Peña, Antonio: escultor (o)

González de la Peña, Nicolás: pintor/dora$\operatorname{dor}(m)$

Guerrero, José: carpintero (o)

Guirado, Manuel: dorador (m)

Guzmán, Manuel: dorador 
Herrera, José de: platero (o)

Hispero Guiral, José: carpintero (m)

Huertas, Isidro de: platero (m)

Hurtado, José: escultor (m)

Jiménez, Félix: dorador (o)

Jiménez, José: carpintero (o)

Laso de la Vega, José: tirador de plata (o)

Lechuga, Felipe: platero (m)

Lechuga, Juan Miguel: platero (o)

León, Salvador de: cantero $(\mathrm{m})$

León Cisneros, José de: tirador de plata $(0)$

Loarte, José: pintor $(m)$

López, Antonio: carpintero (a)

López, Gabriel: dorador (a)

López, Francisco: carpintero (o)

López, Francisco: carpintero (m)

López, José: dorador (o)

López, José: carpintero (a)

López, José Antonio: carpintero (o)

López, Miguel: dorador ( $m$ )

López, Miguel: platero (o)

López, Pedro: cantero (o)

López Portero, Manuel: platero (m)

López Risueño, Juan: tallador (m)

López de Vera, Juan: carpintero (o)

Luengo, Juan: maestro de abrir láminas

Luengo, José de: platero $(\mathrm{m})$

Luque, Francisco de: dorador (o)

Luque, Manuel de: carpintero (o)

Luque, Manuel de: carpintero (o)

Macías, José: carpintero ( $m$ )

Madrigal, Pedro Esteban: tirador de plata (o)

Marchena, Basilio de: pintor $(\mathrm{m})$

Marchena, Francisco: pintor $(\mathrm{m})$

Marchena, Salvador: pintor $(\mathrm{m})$

Marin, Francisco: platero (o)

Marín, José: carpintero (o)

Marín, Juan: pintor $(\mathrm{m})$

Marín, Lorenzo: carpintero (m)

Marín, Salvador: carpintero (0)

Marin, Salvador: platero (0)

Márquez, Francisco: dorador (o)

Martín Barrera, Fernando: carpintero (o)

Martínez, Andrés: cantero (o)

Martinez, Antonio: pintor (a)

Martínez, Francisco: pintor (m)

Martinez, Francisco: platero (a)

Martínez, Francisco Javier: dorador (o)

Martínez, Vicente: dorador (m)

Martos, Manuel de: cantero (m)
Medialdea, Antonio de: aparejador de pintura y bastidores (o)

Medialdea, Mateo: pintor ( $\mathrm{m})$

Medina, Alfonso: carpintero (o)

Medina, Juan de: cantero $(0)$

Medina, Luis de: cantero (0)

Medina, Matías de: cantero (o)

Medina, Victorino de: carpintero (o)

Melgarejo, Nicolás de: bordador (o)

Mendoza, Andrés de: pintor (o)

Mendoza, Diego: pintor $(\mathrm{m})$

Mendoza, José: pintor ( $m$ )

Mendoza, Juan de: profesor de escultura

Mogolión, Antonio de: carpintero (m)

Molina, Juan de: platero ( $m$ )

Molina, Manuel de: cantero (o)

Molina, Martín de: carpintero (m)

Monteagudo, Cristóbal de: carpintero (m)

Morales, Diego: carpintero (o)

Morales, Francisco: carpintero (m)

Morales, Francisco: carpintero (o)

Morales, José de: carpintero (o)

Morales, Juan de: carpintero (m)

Morales, Manuel de: carpintero (o)

Morales, Marcelo: carpintero (m)

Morales, Nicolás: carpintero $(m)$

Morena, José Ventura de la: carpintero (m)

Moreno, Blas: escultor ( $m$ )

Moreno, Juan: bruñidor de piedra (0)

Moya, Nicolás Agustín de: carpintero (m)

Muñoz, Francisco José: platero (o)

Muñoz, Pedro: carpintero (m)

Muriel, Francisco: carpintero (o)

Muriel, Manuel: carpintero (m)

Narváez, Felipe: tallador (o)

Narváez, Pedro: tallador (m)

Navarro, Cristóbal: carpintero (m)

Navarro, Juan: carpintero (o)

Navarro Rivero, Francisco: dorador/pintor (m)

Núñez, Agustín: platero (m)

Núñez, Pedro: carpintero (a)

Núñez, Vicente: carpintero (o)

Ocaña, Antonio de: platero (m)

Olaso Aróstegui, Pedro: carpintero (m)

Ortiz, Pedro: carpintero (m)

Oscos, Sebastián de: carpintero (o)

Otero, Francisco de: cantero (o)

Padilla, Alejandro: platero $(m)$

Páez, Jacinto: platero (m)

Pagán, Bernardo: dorador (o) 
Pagán, Manuel: dorador (a)

Palacios, José: profesor de escultura (m)

Palma, Jerónimo de: maestro mayor de obras de Granada

Palomo (o Palomino), Fernando: carpintero $(\mathrm{m})$

Pareja, Matías: tallador (0)

Párraga, Juan de: profesor de talla

Pavón, Juan: carpintero $(m)$

Peláez, Bartolomé: cantero (m)

Peñas, Antonio de las: carpintero

Peñas, Félix de las: carpintero (o)

Pérez, Alfonso: cantero (o)

Pérez, Benito: tirador de oro/batihoja $(m)$

Pérez, Diego: platero (o)

Pérez, Francisco: pintor (o)

Pérez, Francisco: platero (o)

Pérez, José: platero (a)

Pérez, Nicolás: carpintero (o)

Pérez, Pedro José: cantero (o)

Pérez de Orozco, Juan: carpintero $(m)$

Pino, José del: pintor/dorador ( $\mathrm{m}$ )

Piñero, Agustín: dorador/tirador de oro (o)

Pozo, Francisco del: cantero (o)

Puerta, Mateo de la: platero (o)

Puerta Calderón, Julián de la: platero $(\mathrm{o})$

Quevedo, José: carpintero (m)

Quirós, Fernando: carpintero $(\mathrm{m})$

Quirós, Matías de: carpintero (o)

Ramírez, Juan: cantero (o)

Ramírez de Valdivia, José Ramiro: profesor de escultura $(m)$

Rey, Agustín del: carpintero (o)

Ribera, Antonio: carpintero (o)

Ribera, Francisco: carpintero (m)

Ribera, José: carpintero (o)

Ribera, Juan: carpintero (o)

Ríos, Esteban de los: carpintero (o)

Risueño, Juan: tallador (o)

Rivas, Atanasio de: platero (o)

Rivas, Francisco de: platero (m)

Robles, Tomás de: dorador (o)

Rodríguez, Antonio: carpintero ( $m$ )

Rodríguez, Francisco: carpintero (m)

Rodríguez, Francisco: carpintero (m)

Rodríguez, Joaquín: platero (o)

Rodriguez, Juan: cantero (m)

Rodríguez, Lucas: carpintero (o)

Rojas, Francisco de: carpintero (m)

Rojas, José de: carpintero (o)

Rojas, José de: pintor (o)
Rojas, Manuel de: pintor (a)

Rojas, Matías de: carpintero $(\mathrm{m})$

Rojo, Cecilio: carpintero (o)

Román, Francisco: aparejador de pintura (m)

Román, Juan: carpintero (o)

Román, Pedro Clemente: pintor (o)

Romero, Jerónimo: carpintero (m)

Romero, José: carpintero (o)

Rubio, Alejandro Eugenio del: bordador ( $m$ )

Ruiz, Francisco: bruñidor de piedra (o)

Ruiz, Francisco: pintor (o)

Ruiz, Ginés: ayuda de pintor

Ruiz, Jerónimo: platero (m)

Ruiz, Juan: batihoja (o)

Ruiz, Juan Manuel: dorador (m)

Ruiz, Miguel: cantero (m)

Ruiz, Pedro: dorador $(\mathrm{m})$

Ruiz, Vicente: platero (m)

Ruiz Carrión (o Carrasco), Juan: pintor (o)

Ruiz Dios y Ayuda, Juan: carpintero (m)

Ruiz del Peral, Torcuato: escultor (m)

Ruiz del Rio, José: platero (o)

Ruiz del Río, Tomás: platero (m)

Rul, Manuel de: cantero (o)

Sáez, Juan Miguel: bruñidor de piedra

Salas, Jacinto de: carpintero (o)

Salazar, Juan de: escultor $(\mathrm{m})$

Salcedo, Felipe: pintor ( $m$ )

Salinas, Gabriel de: platero (o)

Salmerón, Alejandro: tallador/ensamblador $(\mathrm{m})$

Salmerón, Juan: tallador (a)

Sánchez, Carlos: platero (o)

Sánchez, Cristóbal: carpintero $(m)$

Sánchez, Cristóbal: pintor (m)

Sánchez, Diego: escultor $(m)$

Sánchez, Eusebio: carpintero (o)

Sánchez, José: carpintero $(\mathrm{m})$

Sánchez, José: carpintero $(\mathrm{m})$

Sánchez, José: carpintero (o)

Sánchez, Leonardo: carpintero $(\mathrm{m})$

Sánchez, Manuel: tallador (o)

Sánchez, Manuel: tailador (o)

Sánchez, Nicolás: carpintero (o)

Sánchez de Escalona, Francisco: carpintero (o)

Santa Cruz, José de: tallador ( $\mathrm{m}$ )

Santander, Agustín de: platero (o)

Santander, Andrés de: platero (m)

Santiago, Alonso: carpintero (o)

Santisteban, Martín: escultor (m)

Santos, Juan de los: bruñidor de piedra (o) 
Santos, Manuel de los: cantero (o) Santos, Manuel de los: carpintero (m)

Sanz, Manuel: cantero (o)

Saravia, Felipe: dorador (o)

Saravia, Francisco: dorador/pintor (m)

Saravia, Isidro: dorador $(m)$

Sedano, Antonio: cantero (o)

Sedano, José: platero (m)

Serrano, Alfonso: tallador $(0)$

Serrano, José: tallador $(\mathrm{m})$

Sevillano, Francisco: pintor (o)

Solano, Lorenzo: platero $(\mathrm{m})$

Talavera, Gabriel de: platero (a)

Talavera, Jerónimo de: platero (o)

Tallón, Manuel: dorador

Tene, Manuel: fiel contraste de platería (m)

Terrones, Diego: cantero (o)

Tójar, Felipe de : carpintero (o)

Tolmos, Miguel de: platero de oro (o)

Toro, Bernardo de: carpintero (o)

Torres, Pedro Antonio de: carpintero $(\mathrm{m})$

Trabado, Isidro: carpintero (o)
Valdés, Antonio: carpintero (o)

Valdivia, Félix José: platero (o)

Valentín, José: carpintero (O)

Valero, Pedro Tomás: escultor $(\mathrm{m})$

Valle, Francisco del: platero (o)

Vargas, José de: carpintero (m)

Vargas Landeras, Silvestre de: cantero (o)

Vázquez, Juan: cantero

Vázquez, Manuel: carpintero (o)

Vera, Agustín de: escultor (m)

Vera, Bernardo de: escultor (o)

Verdallas, Gabriel: carpintero $(\mathrm{m})$

Vergara, Juan de: platero (o)

Victoria, Gregorio: carpintero (o)

Villar, Dionisio del: cantero (m)

Villar, Juan del: cantero $(\mathrm{m})$

Villar, Julián del: cantero (o)

Villoslada, Francisco de: tallador (o)

Villoslada, Nicolás de: tallador (o)

Zamora, Jerónimo: carpintero (o)

Zamora, José: pintor

Zamora, Salvador de: platero (m) 